\title{
Effect of Sn Content on Filler and Bonding Characteristics of Active Metal Brazed $\mathrm{Cu} / \mathrm{Al}_{2} \mathrm{O}_{3}$ Joint
}

\author{
Jioh Shin', Ashutosh Sharma ${ }^{2}$, Do-hyun Jung ${ }^{1}$, and Jae Pil Jung,* \\ ${ }^{1}$ Department of Materials Science and Engineering, University of Seoul, Seoul 02504, Republic of Korea \\ ${ }^{2}$ Department of Energy Systems Research, Ajou University, Suwon 16499, Republic of Korea
}

\begin{abstract}
This study examined the effects of the $\mathrm{Sn}$ content in a pure active metal filler $\mathrm{Ag}-\mathrm{Cu}-\mathrm{Ti}$ for the brazing of a Cu/ $\mathrm{Al}_{2} \mathrm{O}_{3}$ joint. The optimal content of $\mathrm{Sn}$ to effectively wet alumina was 5 wt\%. The microstructure of the brazed joint showed the presence of an Ag-rich matrix and a Cu-rich phase, and $\mathrm{Cu}$ Ti intermetallic compounds were observed along the bonded interface. The intermetallic compounds (IMCs) in the filler are found to increase when the $\mathrm{Sn}$ content in the alloy approaches to $10 \mathrm{wt} \%$. These results suggest an extremely significant bonding strength of $\mathrm{Cu} / \mathrm{Al}_{2} \mathrm{O}_{3}$ joint using the $\mathrm{Ag}-\mathrm{Cu}-\mathrm{Ti}+\mathrm{Sn}$ filler. The shear strength of the brazed joint increased with Sn content up to $5 \mathrm{wt} \%$, reaching a maximum at $\approx 15 \mathrm{MPa}$. In addition, the strength decreased when the Sn content was higher than 5 wt\%.
\end{abstract}

(Received January 10, 2018; Accepted March 6, 2018)

Keywords: metal, active brazing, diffusion, intermetallic compounds, alumina.

\section{INTRODUCTION}

Alumina is the choice of material for range of structural and functional applications because of its attractive properties, such as higher strength, higher fracture toughness and hardness, good high temperature properties, and low dielectric constant [1-4]. In various practical applications, alumina needs to be joined with metals or ceramics in complex geometry equipment, e.g., in automotive and electronics, $\mathrm{Cu} / \mathrm{Al}_{2} \mathrm{O}_{3}$ contacts in relay devices, micro-electro-mechanical systems (MEMS), aerospace and thermoelectric power generation, and other areas [4-10]. On the other hand, ceramics are chemically inert owing to their strong covalent bonding, and are not usually wetted by most traditional brazing fillers [11]. Active elements, such as $\mathrm{Ti}, \mathrm{Zr}$ or $\mathrm{Nb}$, are added to the silver-based alloys to improve the wettability [12]. If, however, more amount of $\mathrm{Ti}$ is present, wetting can be improved up to a critical temperature $\left(>800^{\circ} \mathrm{C}\right)$, and then it may react with the ceramic materials above that critical temperature

*Corresponding Author: Jae Pil Jung

[Tel: +82-2-6490-2408, E-mail: jpjung@uos.ac.kr]

Copyright (c) The Korean Institute of Metals and Materials
$[13,14]$. Therefore, increasing the amount of active elements, such as $\mathrm{Ti}$ is not good for a robust joint. The wettability of the substrates is very important for the proper selection of filler alloy in micro-joining but not at the cost of joint strength due to uncontrolled IMCs [15-18]. In addition, the coefficient of thermal expansion (CTE) is a serious concern in ceramic-metal joining, which builds up significant residual stresses at the interface. In addition, the chemical compositions of the contact components and their performance at working temperatures also contribute [12]. Active metal brazing is also attractive in dental research for joining $\mathrm{ZrO}_{2}$ crowns to Ti-based abutment-implant systems, which is not possible using conventional fusion welding techniques $[19,20]$. For ceramic-metal combinations, various brazing alloys, such as $\mathrm{Ag}-\mathrm{Cu}$, Ag-Cu-Ti, Cu-Sn-Ti, Cu-Ni-Ti, etc., have been investigated [19-23]. Recently, the use of composite fillers, such as $\mathrm{Ag}-\mathrm{Cu}-\mathrm{Ti}-\mathrm{SiC}$ and $\mathrm{Ag}-\mathrm{Cu}-\mathrm{Ti}-\mathrm{TiX}$, to braze ceramicmetal joints have also been attempted [24,25]. On the other hand, the segregation of ceramic nanomaterials in composite fillers a serious issue that cannot be tolerated. Among these, the most popular one is $\mathrm{Ag}-\mathrm{Cu}-$ $\mathrm{Ti}$ because its excellent fluidity and wetting can be 
applied to join $\mathrm{Cu} / \mathrm{Al}_{2} \mathrm{O}_{3}$ joint. The purpose of this investigation was to study the microstructural evolution of Ag-Cu-Ti and its wetting ability to alumina with different Sn contents. Sn was added into the filler alloy to control the intense reaction among $\mathrm{Cu}$, Ti and substrates. More importantly, the melting point of filler alloy was lowered by adding Sn. In addition, the tensile shear strength and microhardness of the joint interface $\left(\mathrm{Cu} / \mathrm{Al}_{2} \mathrm{O}_{3}\right)$ were also estimated.

\section{MATERIALS and METHODS}

\subsection{Materials and methods}

The substrate materials were copper and alumina (purity $>92 \%$ ). The alumina plates (dimensions: 15 $\mathrm{mm} \times 15 \mathrm{~mm} \times 5 \mathrm{~mm}$ ) and $\mathrm{Cu}$ plates (>99.99\%) in dimensions of $20 \mathrm{~mm} \times 20 \mathrm{~mm} \times 5 \mathrm{~mm}$ were purchased from Korea Electronic Material Company Gyeonggi-Do, Korea, and Daeduck Metals Company, South Korea, respectively. The top surface of the $\mathrm{Al}_{2} \mathrm{O}_{3}$ and $\mathrm{Cu}$ plates were ground using $\mathrm{SiC}$ papers (\#1000, 2000, 2400,4000 ) and polished with $\mathrm{Al}_{2} \mathrm{O}_{3}$ alumina suspension and diamond paste $(1 \mu \mathrm{m})$ on a Buehler Auto Polisher machine using standard metallographic techniques. Table 1 lists the composition of the alumina and copper plates.

Table 1. Composition of the contact substrates.

\begin{tabular}{ccccc}
\hline Copper & $\mathrm{Cu}$ & & & \\
\hline (wt\%) & 99.99 & & & \\
\hline Alumina & $\mathrm{Al}_{2} \mathrm{O}_{3}$ & $\mathrm{SiO}_{2}$ & $\mathrm{MnO}_{2}$ & $\mathrm{MgO}$ \\
\hline$($ wt $\%)$ & 92 & 4 & 3 & 1 \\
\hline
\end{tabular}

\subsection{Brazing filler preparation}

Four different types of active braze alloys with different $\mathrm{Sn}$ contents were used in the experiment, as shown in Table 2.

To prepare the filler metal, $\mathrm{Ag}, \mathrm{Cu}, \mathrm{Sn}$, and $\mathrm{Ti}$ powders at the selected compositions were taken and blended in an Attritor mill (Model: Planetary Ball
Table 2. Composition of the filler materials.

\begin{tabular}{ccccc}
\hline \multirow{2}{*}{ Sample } & \multicolumn{5}{c}{ Composition (wt\%) } \\
\cline { 2 - 5 } & $\mathrm{Ag}$ & $\mathrm{Cu}$ & $\mathrm{Ti}$ & $\mathrm{Sn}$ \\
\hline $\mathrm{C} 1$ & 72 & 26 & 2 & 0 \\
\hline $\mathrm{C} 2$ & 69 & 26 & 2 & 3 \\
\hline $\mathrm{C} 3$ & 67 & 28 & 2 & 5 \\
\hline $\mathrm{C} 4$ & 65 & 28 & 2 & 10 \\
\hline
\end{tabular}

Mill PM 100 Retsch, Germany). Milling was performed for 24 hours to obtain a uniform mixing of metal powders. After milling, the mixed powder samples were melted around $1050{ }^{\circ} \mathrm{C}$ in a vacuum furnace for 30 minutes. The samples were re-melted approximately three times to avoid the inhomogeneity of the braze alloy. The weight reduction of the final filler alloy was $\approx 1 \mathrm{wt} \%$.

\subsection{Brazing Joint preparation}

The samples $\left(\mathrm{Al}_{2} \mathrm{O}_{3}\right)$ and $\mathrm{Cu}$ were brazed in a direct face to face joint geometry, as shown in Fig. 1.

Before brazing, the contact surfaces were finely polished and cleaned with ethanol and ultrasonicated for 30 minutes to remove adherent impurities and grease followed by drying in a low-temperature oven. Brazing was performed in a vacuum furnace under a pressure of $5 \times 10^{-6}$ Torr at $980{ }^{\circ} \mathrm{C}$ for a holding time of $30 \mathrm{~min}$. For different samples, brazing was per-

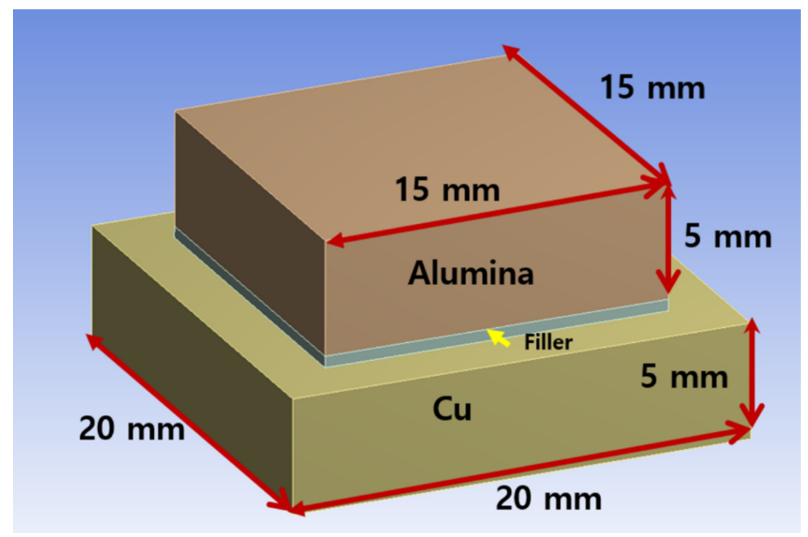

Fig. 1. Schematic diagram of the brazing sample.

Table 3. Brazing parameters used in this study.

\begin{tabular}{ccccc}
\hline Parameter & Heating temperature & Holding time & Heating/cooling rate & Vaccum \\
\hline Values & $980^{\circ} \mathrm{C}$ & $5 \mathrm{~min}$. & $10^{\circ} \mathrm{C}$ & $5 \times 10^{-5}$ \\
\hline
\end{tabular}


formed under identical conditions (Table 3) in a VAF20 vacuum furnace.

\subsection{Microstructural investigation}

X-ray diffraction (XRD, Bruker's D8 Discover) was performed for the structural investigations. The microstructure of the bulk filler and joints was observed by field emission scanning electron microscopy (FESEM, Hitachi S-4300). For bonded specimens, the joints were sectioned by a low-speed diamond saw and polished using the metallographic procedures as described earlier. An etching solution of $\mathrm{FeCl}_{3}, \mathrm{H}_{2} \mathrm{O}, \mathrm{HCl}$, and $\mathrm{C}_{2} \mathrm{H}_{5} \mathrm{OH}$ was also used for metallographic examination. Quantitative compositional analysis was performed by electron probe micro-analysis (EPMA, JEOL JXL-8800M).

\subsection{Wettability analysis}

The contact surfaces $(30 \mathrm{~mm} \times 30 \mathrm{~mm} \times 0.3 \mathrm{~mm})$ were well-polished and cleaned with alcohol and dried. Figure 2 presents a schematic diagram of spreading.

The measurement of spread was accomplished by

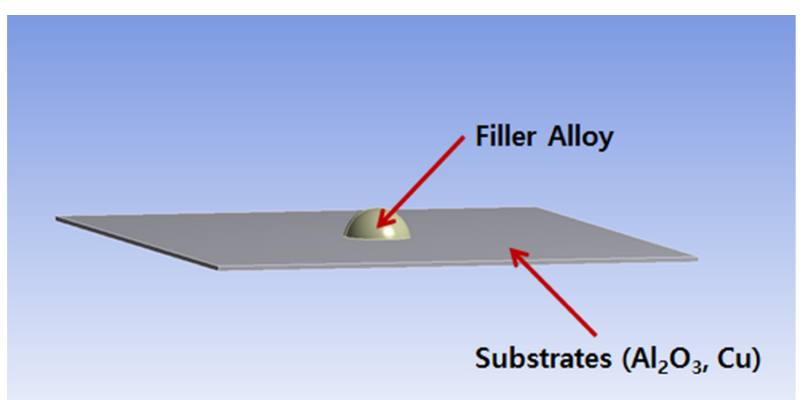

Fig. 2. Schematic diagram for the spreading ratio measurement.

measuring the spread ratio according to the change in spread shape and geometry: [26]

$$
S=\frac{D-H}{D} x 100
$$

Here, $\mathrm{S}$ is the filler spread ratio; $\mathrm{H}$ is the height of the filler spread; and D is the diameter of the filler when it is assumed to be a sphere $\left(D=1.24 q^{1 / 3}\right)$, where $\mathrm{q}$ is the mass per unit density of the filler.

A total of 5 measurements were taken on different specimens each time. Approximately $0.3 \mathrm{~g}$ filler was mixed with $0.03 \mathrm{~g}$ of Ag brazing flux (Ultra Flux, Lucas-Milhaupt) during the spreading test. The resulting paste was applied to the center of the contact substrates, heated for $30 \mathrm{sec}$ and cooled to room temperature. The change in height and spread area was measured using a micrometer.

\subsection{Measurement of hardness (bulk filler)}

The microhardness of the filler alloy with different compositions was tested using a Mitutoyo MVK H1 hardness testing machine. The loading force applied was $25 \mathrm{gf}$ for a dwell time of 10 seconds. The indentation diameters obtained were transformed to Vickers' microhardness according to the equation,

Microhardness $=1.854$ times $\left(\mathrm{P} / \mathrm{D}^{2}\right)$

Where $P$ is the loading force (in $\mathrm{kgf}$ ), and $D$ is the diameter of indentation (in $\mathrm{mm}$ ). Five random measurements were performed and the average value is reported as the actual hardness of the alloy.

\subsection{Measurement of tensile shear strength}

A joint tensile-shear test was conducted in a face to face bonding geometry, as shown in Fig. 3. The tests were performed at a crosshead speed of $5 \mathrm{~mm} /$ minute using a precision universal testing machine with a 5ton press (UTM DUT-30000 CM, Dae Kyung Engineering, Korea) according to Ref [27]. The UTS and the strain values were calculated from the tensile shear stress-strain diagrams.

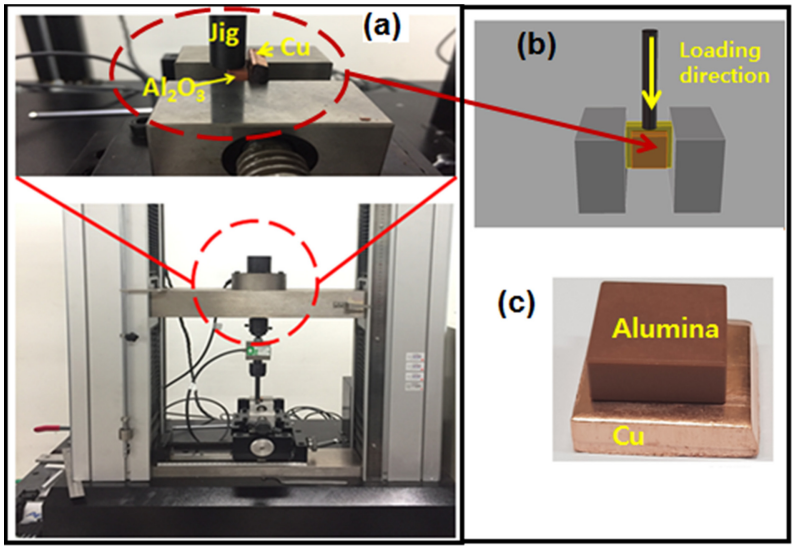

Fig. 3. (a) Schematic diagram of the shear test set-up, (b) close view of the sample, and (c) actual bonded sample. 


\section{RESULTS}

\subsection{Bulk filler}

Figure 4 shows XRD patterns of the various fillers investigated. Several peaks were observed indicating $\mathrm{Cu}, \mathrm{Ag}$, and other intermediate phases, such as TiOx, $\mathrm{Cu}, \mathrm{Cu}_{3} \mathrm{Ti}$, and $\mathrm{Ti}_{3} \mathrm{Sn}$ which are critical to the joint performance $[27,28]$. The result is in consistent with Ref [29]. The existence of $\mathrm{Ti}$ and its compound at the intermediate layer will improve the bonding strength between the $\mathrm{Cu}$ and $\mathrm{Al}_{2} \mathrm{O}_{3}$. As the intensity of the IMCs increased with $\mathrm{Sn}$ additions, the formation of $\mathrm{Ti}-\mathrm{Sn}$ and $\mathrm{Cu}-\mathrm{Ti}$ compounds increased, and the bonding strength increased. On the other hand, the TiOx peak decreased when $10 \mathrm{wt} \%$ Sn was added. This may be due to the unavailability of more $\mathrm{Ti}$ for the reaction and hence a weakening of the activity of Ti metal, causing a decrease in wetting. This result is in agreement with other studies [24,25, 27-29].

XRD analyses indicate that in all cases, the brazing alloys reacted chemically with the joining surfaces, which is a primary criterion for strong and reliable joint formation. Peak broadening also occurred when $\mathrm{Sn}$ was added to the Ag-Cu-Ti filler, which shows the dissolution of the $\mathrm{Sn}$ constituents. The presence of $\mathrm{Cu}_{3} \mathrm{Ti}$ and residual $\mathrm{Ti}$ was also observed. At higher $\mathrm{Sn}$ contents, Ti reacts with sufficient $\mathrm{Sn}$ forming

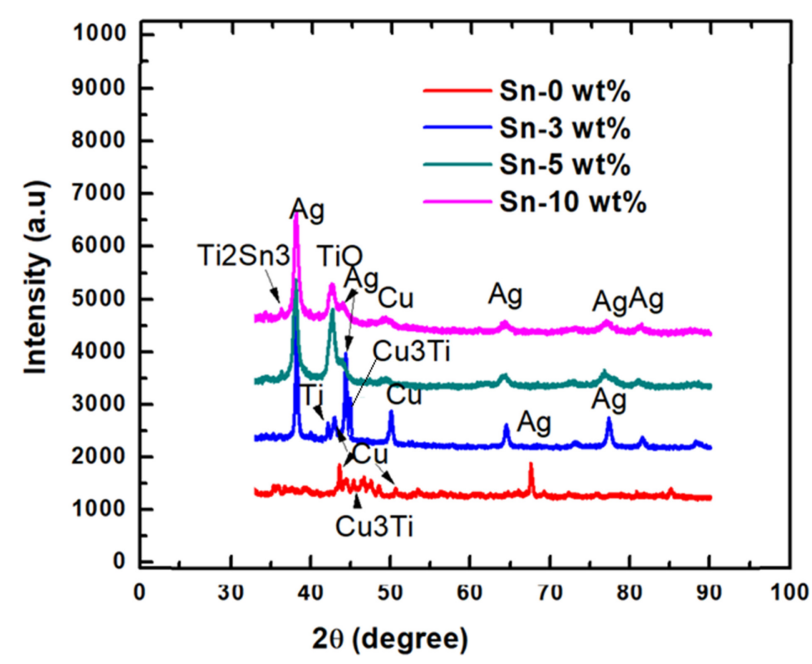

Fig. 4. XRD pattern of the filler alloy as a function of $\mathrm{Sn}$ concentration.
$\mathrm{Ti}_{3} \mathrm{Sn}$ and $\mathrm{TiO}$ so that all the $\mathrm{Ti}$ is consumed at $\mathrm{Sn}=10 \mathrm{wt} \%$. Owing to consumption of active metal $\mathrm{Ti}$, the bonding may become weaker, reducing the formation of $\mathrm{Cu}_{3} \mathrm{Ti}$ IMCs

\subsection{Wetting}

Increasing the $\mathrm{Sn}$ content in $\mathrm{Ag}-\mathrm{Cu}-\mathrm{Ti}$ alloy from 0 to $10 \mathrm{wt} \%$ resulted in a marked variations in the spreading behavior of the filler on the substrates. Both substrates were used: copper and alumina. Figure 5 shows the measured spreading ratios of the different samples.

The spreading ratio $(\mathrm{S})$ increased until the $\mathrm{Sn}$ content reached $5 \mathrm{wt} \%$ and then decreased rapidly thereafter. The $\mathrm{S}$ of the pure $\mathrm{Ag}-\mathrm{Cu}-\mathrm{Ti}$ was approximately $85 \%$ on alumina and $88 \%$ on $\mathrm{Cu}$, which reached a maximum at $5 \mathrm{wt} \% \mathrm{Sn}$, approaching approximately $89 \%$ on alumina and $97 \%$ on $\mathrm{Cu}$. The $\mathrm{S}$ again decreased for sample $\mathrm{C} 4$ (i.e., Sn: $10 \mathrm{wt} \%$ ) reaching up to $90 \%$ on copper but only $65 \%$ on alumina. This was attributed to the close association between pure $\mathrm{Ag}-\mathrm{Cu}-\mathrm{Ti}$ and $\mathrm{Sn}$. In other words, when most of the $\mathrm{Sn}$ is consumed, the active metal $\mathrm{Ti}$ cannot participate in the reactive wetting of alumina [27]. Therefore, the $\mathrm{S}$ decreases when the $\mathrm{Sn}$ content exceeds $5 \mathrm{wt} \%$, indicating the poor wetting ability of Ag-Cu-Ti fillers. Although the $\mathrm{S}$ was considerably smaller on alumina, it decreased slightly on copper

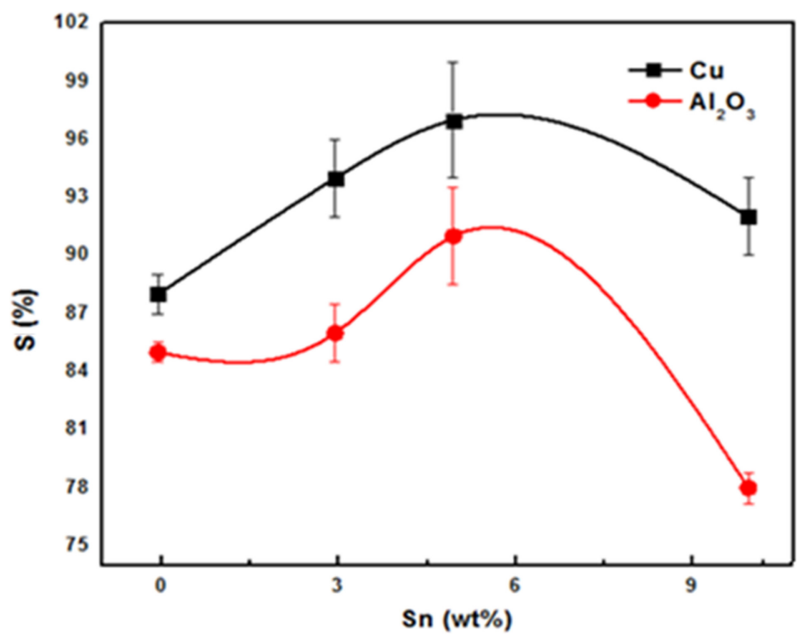

Fig. 5. Calculated spreading ratios of different samples. 

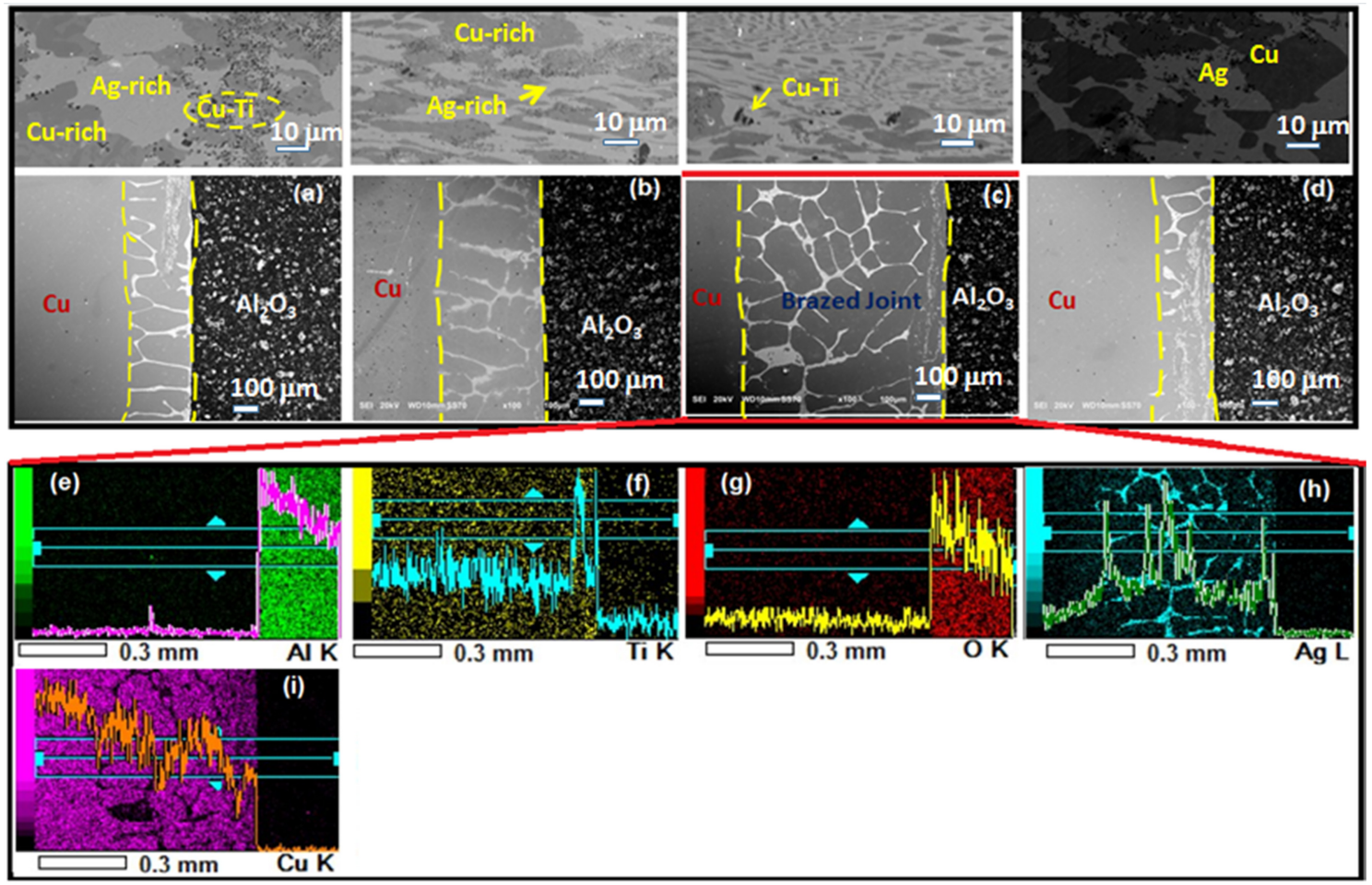

Fig. 6. (a-d) Surface morphology of the joint showing plane surface SEM and the corresponding interface, and (e-i) EPMA of the joint with Ag-Cu-Ti-5 wt $\%$ Sn.

substrates. This may be obvious due to the inertness of the ceramic and strong covalent bonding compared to the metallic bonding in metals. Based on these observations, Ag-Cu-Ti-5 wt $\%$ Sn showed good performance in the wettability tests on both copper and alumina.

\subsection{Bonded joint characteristics}

Figure 6 presents SEM images of the joint interface between $\mathrm{Al}_{2} \mathrm{O}_{3}$ and $\mathrm{Cu}$ brazed with a filler containing different $\mathrm{Sn}$ contents at $980{ }^{\circ} \mathrm{C}$. An enhanced image of the interface can be found on the top of each joint image (Fig. a-d). At low resolution at the interfacial region, various bright networks of different phases were observed. The interface layer thickness increases in the order of 190, 280, 580, and $110 \mu \mathrm{m}$ reaching a maximum for the $\mathrm{C} 3$ sample. This suggests that the active metal bonded ratio of the interface increases as the bonding progresses up to sample C3. On the other hand, insufficient bonding was observed in the $\mathrm{C} 1$ and $\mathrm{C} 4$ samples, whereas enhanced bonding was present in $\mathrm{C} 2$ and $\mathrm{C} 3$. An examination of sample C3 (Ag-Cu-Ti-5 wt\% Sn) at a higher resolution (images on top of Fig. 6a-d) revealed various dark and white patches along with a fine layer near the contact surface $\mathrm{Cu}$ (Fig. 6e-i).

The joint characteristics at higher resolution show that the active filler diffuses into the alumina part due to some open pores existing at the surface. Because the alumina is $92 \%$ pure; there are some open pores caused by minor impurities. In addition, the diffusivity can also be attributed to the mechanism of capillary action of the filler on the alumina side in the joint $[14,15]$. The diffusion of filler into the ceramic leads to its reaction with the oxide forming aggregate spots in the alumina substrate [14]. These aggregate spots may improve the joining and strength further. Across the copper side, a close inspection of Fig. 6 revealed the presence of 3 different regions in the SEM image, alumina, $\mathrm{Cu}$ and the IMCs within the interface region between them. The interface consists of $\mathrm{Cu}$-Ti IMCs between the 

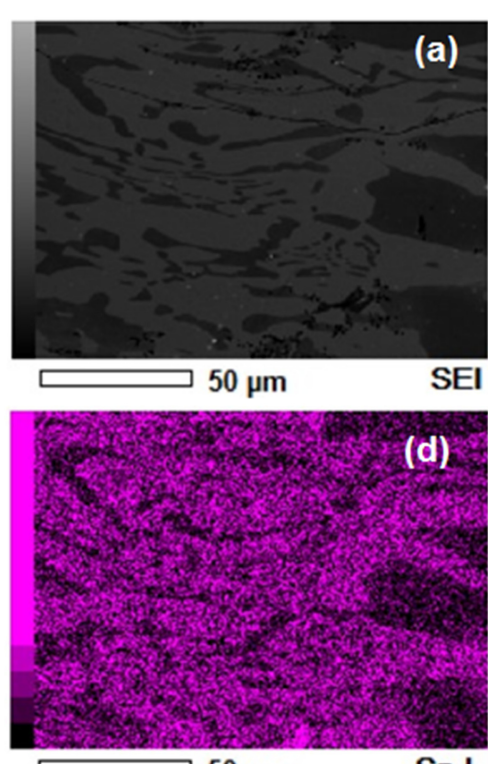

$50 \mu \mathrm{m}$

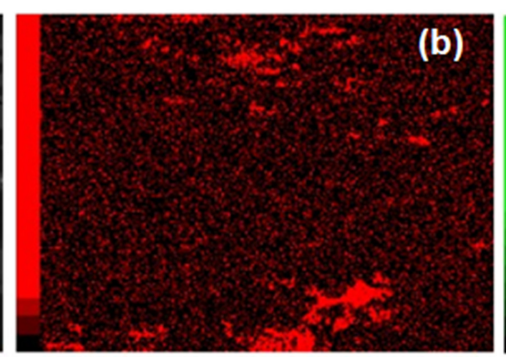

Ti K

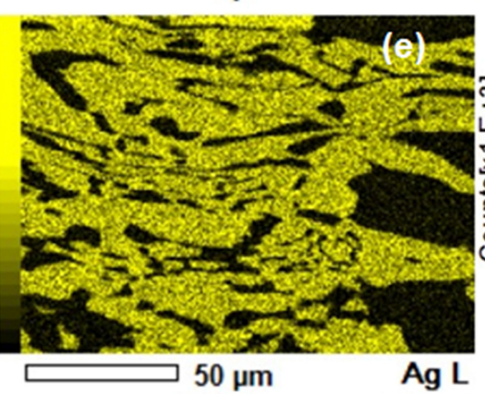

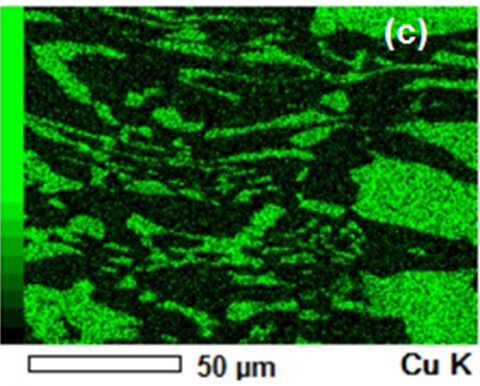

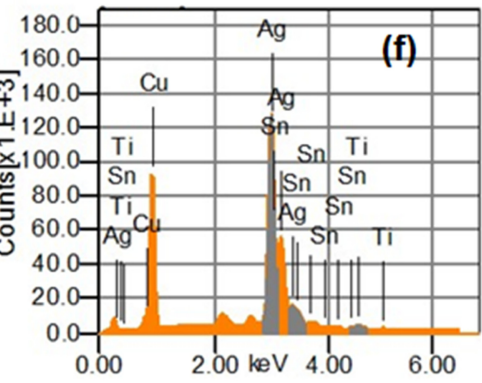

Fig. 7. (a-e) EPMA analysis at the center of the joint, and (f) EDS analysis across the joint

filler metal and $\mathrm{Cu}$, and indicates $\mathrm{Cu}$-rich and $\mathrm{Ag}$ rich constituents, respectively. These results are consistent with other reports on ceramic-metal joining [2027]. The elementalal distribution across the interface was observed by EPMA. Figure 7 shows the EPMA elemental maps of the interfacial region. The diffusion of $\mathrm{Cu}$ from the $\mathrm{Cu}$ surface and $\mathrm{Ti}$ from the filler metal form various $\mathrm{Cu}-\mathrm{Ti}$ IMCs and cause a stronger metal bond at the interface. The atomic $\%$ ratios of $\mathrm{Cu}$ and $\mathrm{Ti}$ were approximately $\sim 1: 1$ to $1: 3$ at different regions. Moreover, $\mathrm{Cu}(\sim 85.72 \%)$ was detected strongly in sample $\mathrm{C} 4$, and $\mathrm{Ag}$ and $\mathrm{Sn}(>$ $80 \%$ ) was most prominent across the interface. This shows that the large black particles are unreacted $\mathrm{Cu}$; hence, bonding is poor in sample C4. The other elements were present in smaller amounts. Ti was distributed predominantly in the form of $\mathrm{CuTi}$, and $\mathrm{CuTi}_{3}$; CuTi was closer to the copper surface. The consumption of $\mathrm{Ti}$ increased with increasing $\mathrm{Sn}$ content (Table 3) due to an increase in $\mathrm{Sn} / \mathrm{Ti}$ ratio, causing a weakening in the $\mathrm{Cu}-\mathrm{Ti}$ interaction and forming Ti-Sn, hence poor joining in the $\mathrm{C} 4$ sample. Therefore, the bonding strength may degrade due to uneven joining, as confirmed by the wettability measurements.

\subsection{Hardness}

Figure 8 shows the microhardness of the filler with different Sn concentrations. The microhardness of the $\mathrm{C} 2$ sample was poor compared to $\mathrm{C} 1$. Moreover, Sn became effective towards microhardness improvement only when it was added at $5 \mathrm{wt} \%$ or more. The microhardness varied from $\sim 114$ to $129 \mathrm{Hv}$, showing a considerable increase in the microhardness of filler alloys for samples $\mathrm{C} 3$ and $\mathrm{C} 4$. This shows that the presence of Sn enhances the fluidity of the filler and

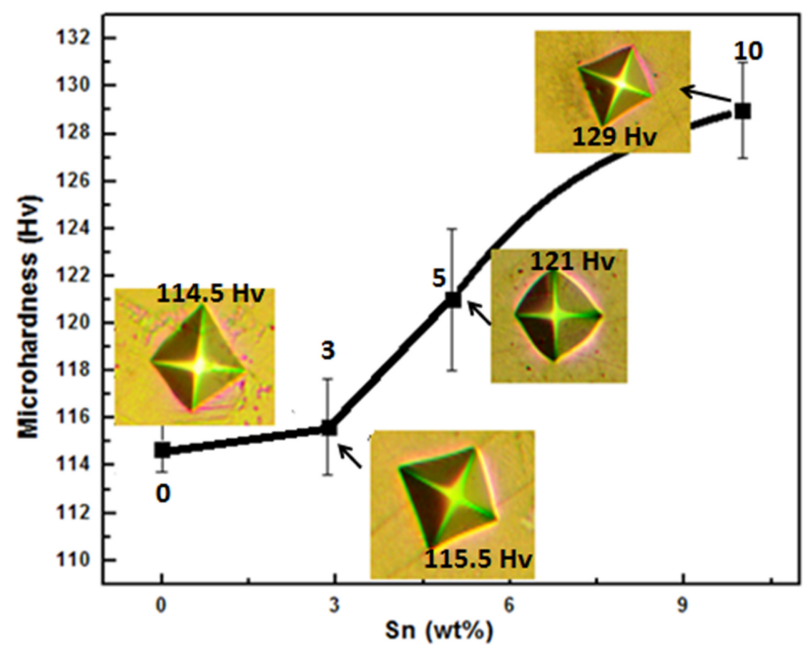

Fig. 8. Microhardness of the Ag-Cu-Ti fillers as a function of $\mathrm{Sn}$ 

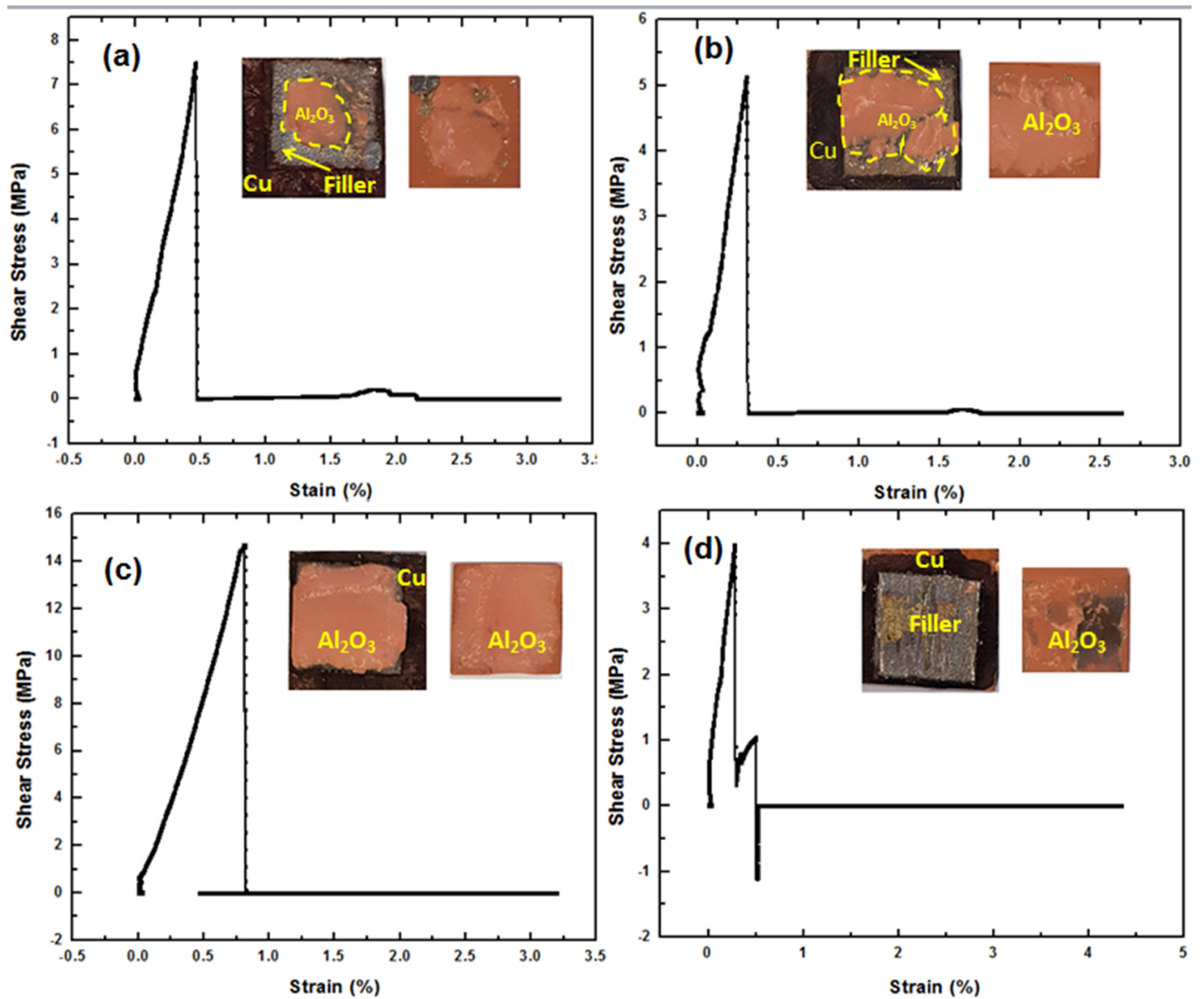

Fig. 9. Shear stress-strain curves of the $\mathrm{Cu} / \mathrm{Al}_{2} \mathrm{O}_{3}$ joints brazed with different alloys, (a) Ag-Cu-Ti, (b) Ag-Cu-Ti-3 wt $\% \mathrm{Sn}$, (c) Ag-Cu-Ti-5 $\mathrm{wt} \% \mathrm{Sn}$, and (d) Ag-Cu-Ti-10 wt $\% \mathrm{Sn}$

fills the gap between the pores in the alumina substrate, thereby causing sufficient densification and interactions of the filler constituents. The microstructural evolution brought about by the densification process would partially affect the hardness. This could also be related to the fine microstructure brought about by the presence of fine $\mathrm{Cu}-\mathrm{Ti} \mathrm{IMCs}$ in the Ag-Cu-Ti matrix (Fig. 8).

\subsection{Shear strength}

The maximum shear stress was selected as the bonding strength before fracture occurs. Figure 9a shows the results of the shear strength of the bonded $\mathrm{Cu} / \mathrm{Al}_{2} \mathrm{O}_{3}$ sample using an active metal filler containing different $w \mathrm{t} \% \mathrm{Sn}$. In all cases, fracture occurred at the alumina side with the detachment of the alumina layer, as shown in the inset images. The measured bond strength of the samples was 7.5, 5.5,
14.5, and $4 \mathrm{MPa}$, respectively. Sample C3 showed the maximum shear strength, whereas it was degraded for samples $\mathrm{C} 4, \mathrm{C} 2$, and $\mathrm{C} 1$ respectively.

\subsection{Fracture surface morphology}

To examine the fracture mechanism, the fracture surfaces of sample $\mathrm{C} 4(10 \mathrm{wt} \% \mathrm{Sn})$ were analyzed by EPMA, as shown in Fig. 10(a-h).

From the previous sections, all the samples were fractured in an irregular manner. On the other hand, the filler containing $10 \mathrm{wt} \% \mathrm{Sn}$ was selected for fracture analysis because it had a poor fracture strength and was found to be suitable for identifying the fracture mechanism. The fracture surface had an uneven surface (Fig. 10a). The EPMA elemental maps (Fig. 10b-g) and EDS (Fig. 10h) revealed the composition of the fractured joint. Based on the compositional analyses, as shown in Fig. 10a, the 
fracture surface could be divided into two regions, one with a filler metal (ductile region fracture) and IMCs and another with a fractured surface detached from the alumina (depicting the brittle fracture region). ). As the bonding interface thickness was lowest in sample C4, the alumina surface was detached easily, even at smaller loads but no fracture was observed near the copper region. This may be due to the increasing $\mathrm{Sn} / \mathrm{Ti}$ ratio and progressive consumption of the Ti metal simultaneously, which causes the weak diffusion of $\mathrm{Cu}$ atoms with $\mathrm{Ti}$ of the filler. This was confirmed by the large copper particles in sample $\mathrm{C} 4$ and the lowest interface thickness (ref Fig. 6). Therefore, $\mathrm{Sn}=5 \mathrm{wt} \%$ can seal the pores of alumina and achieve an optimal $\mathrm{Ti} / \mathrm{Sn}$ ratio for the high activity of $\mathrm{Ti}$ metal towards joining.

\section{CONCLUSIONS}

This study examined the brazing of $\mathrm{Al}_{2} \mathrm{O}_{3}$ to $\mathrm{Cu}$ using $\mathrm{Ag}-\mathrm{Cu}-\mathrm{Ti}+\mathrm{Sn}$ filler. The conclusions can be summarized as follows:

(1) The brazing alloy was composed of an $\mathrm{Ag}, \mathrm{Cu}-$ based solid solution and Sn particles together with $\mathrm{Ti}$ reaction phases.

(2) XRD showed that the reaction between $\mathrm{Ti}$ and $\mathrm{Sn}$ particles proceeds slowly initially, and $\mathrm{Ti}$ reacts with $\mathrm{Sn}$ to form a Ti-Sn based compound. The typical microstructure of the brazed joint with $\mathrm{Ag}-\mathrm{Cu}-\mathrm{Ti}$ + Sn filler is $\mathrm{Al}_{2} \mathrm{O}_{3} / \mathrm{TiOx} / \mathrm{Cu}_{3} \mathrm{Ti}$, Ti-Sn-O, and $\mathrm{Cu}-\mathrm{Ti} / \mathrm{Cu}$.

(3) Shear strength testing showed that the optimal brazing conditions for the $\mathrm{Ag}-\mathrm{Cu}-\mathrm{Ti}$ were observed at the $5 \mathrm{wt} \% \mathrm{Sn}$, i.e., $980{ }^{\circ} \mathrm{C}$ for $30 \mathrm{~min}$, which yielded the highest tensile strength of $\approx 15 \mathrm{MPa}$.

(4) The Ag-Cu-Ti $+\mathrm{Sn}$ filler produced slightly higher shear strengths than those obtained with the pure Ag-Cu-Ti. The shear strength reached a maximum at $5 \mathrm{wt} \% \mathrm{Sn}$ because a more appropriate interfacial reaction layer formed and a suitable reaction with the Sn particles in the seam.

(5) Fracture analyses showed that brittle fracture occurs across the alumina surface, irrespective of the sample compositions. The fractured area across the alumina layer reached a maximum at $5 \mathrm{wt} \% \mathrm{Sn}$. This may be due to the highest fluidity of $\mathrm{Sn}$ across the joint that sealed the alumina layer effectively and increased bonding

\section{ACKNOWLEDGEMENTS}

This work was supported by the Technology development Program (S2517123) funded by the Ministry of SMEs and Startups (MSS, Korea).

\section{REFERENCES}

1. R. Asthana and M. Singh, J. Eur. Ceram. Soc. 28, 617 (2008).

2. A. Bellosi, C. Galassi, and S. Guicciardi, J. Mater. Sci. 25, 4331 (1990).

3. G. M. Liu, G. S. Zou, A. P. Wu, and D. K. Zhang, Mater. Sci. Eng. A 415, 213e218 (2006).

4. R.W. Smith, Weld. J. 80, 30 (2001).

5. Y. Gan, D. Lee, X. Chen, and J. W. Kysar, J. Eng. Mater. Technol. 127, 451 (2005).

6. C. Scheu, S. Klein, A. P. Tomssia, and M. Ruhle, J. Microsc. 208, 11 (2002).

7. R. Nadipalli, J. Fan, H. K. H. Lee, K. H. Wee, H. Yu, and C. S. Tan, Proc. IEEE International 3D System Integration Conference, Osaka, Japan (2011).

8. A. Sharma, J. H. Lee, K. H. Kim, and J. P. Jung, J. Microelectron. Packag. Soc. 24, 9 (2017).

9. D. H. Jung, A. Sharma, K. H. Kim, Y. C. Choo, and J. P. Jung, J. Mater. Eng. Perform. 24, 1107 (2015).

10. A. Sharma, D. H. Jung, M. H. Roh, and J. P. Jung, Electron. Mater. Lett. 12, 856 (2016).

11. W. D. Kingery, H. K. Bowen, and D. R. Uhlmann, Introduction to Ceramics, $2^{\text {nd }} e d$. Wiley Inter-science, USA (1976).

12. R. M. do Nascimento, A. E. Martinelli, and A. J. A. Buschinelli, Ceramica 49, 178 (2003).

13. I. Foroutan, R. S. Mamoory, and N. Hosseinabadi, Ceram. Int. 36, 741 (2010).

14. P. Mishra, S. Athavale, A. Pappachan, A. Grover, A. Suri, P. Sengupta, G. Kale, K. Bhanumurthy, and P. De, Metall. Mater. Trans. A 36, 1487 (2005).

15. A. Sharma, D.-U. Lim, and J.-P. Jung, Mater. Sci. Technol. 32, 773 (2016). 
16. A. Sharma, M.-H. Roh, D. H. Jung, and J. P. Jung, Metall. Mater. Trans. A 47, 510 (2016).

17. A. Sharma, M. H. Roh, and J. P. Jung, J. Mater. Eng. Perform. 25, 3538 (2016).

18. A. Sharma, H.-R. Sohn, and J. P. Jung, Metall. Mater. Trans. A 47, 494 (2016).

19. A. Sharma, S. H. Kee, F. Jung, Y. Heo, and J. P. Jung, J. Mater. Eng. Perform. 25, 1722 (2016).

20. S. H. Kee, J. P. Jung, and W. J. Kim, JWJ 32, 40 (2014).

21. C. C. Lin, R.-B. Chen, and R.-K. Shiue, J. Mater. Sci. 36, 2145 (2001).

22. Y. Wang, J. C. Feng, L. X. Zhang, P. He, and J. H. Zhang, Mater. Sci. Technol. 23, 320 (2007).

23. C. T. Chang and R. K. Shiue, Int. J. Refract. Met. H. 23, 161
(2005).

24. Y. M. He, J. Zhang, C. F. Liu, and Y. Sun, Mater. Sci. Eng. A 527, 2819 (2010).

25. Q. Miao, W. Ding, Y. Zhu, Z. Chen, J. Xu, and C. Yang, Ceram. Int. 42, 13723 (2016).

26. A. Sharma, B. G. Baek, and J. P. Jung, Mater. Design 87, 370 (2015).

27. K. Nagatsuka, S. Yoshida, Y. Sechi, and K. Nakata, Sci. Technol. Weld. Joi. 19, 521 (2014).

28. H. Y. Lee, A. Sharma, S. H. Kee, Y. W. Lee, J. T. Moon, and J. P. Jung, Electron. Mater. Lett. 10, 997 (2014).

29. C.-Y. Su, X. Z. Zhuang, and C.-T. Pan, J. Mater. Eng. Perform. 23, 906 (2014). 